\title{
Olimpia im Cyberland
}

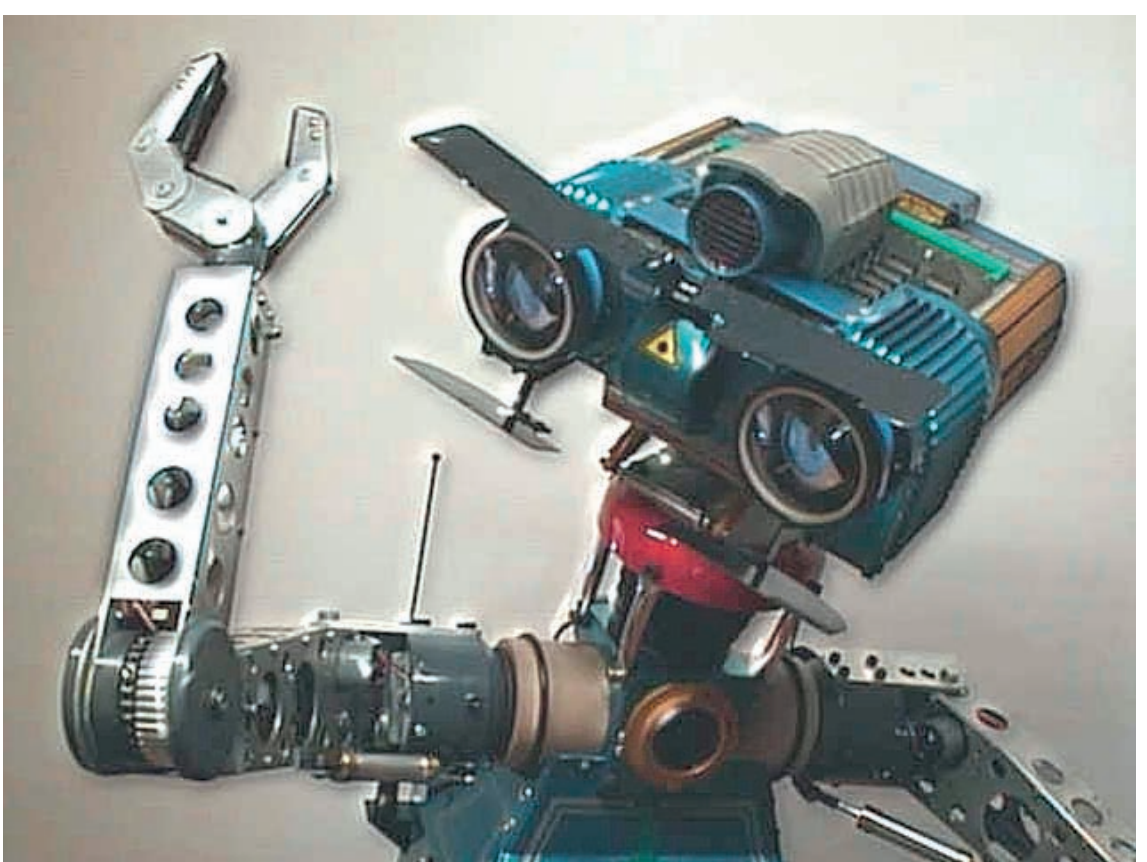

Erhard Taverna
Zu den bekanntesten Erzählungen von E. T. A. Hoffmann gehört «Der Sandmann» (1816). Die tragische Geschichte des Studenten Nathanael, der sich ahnungslos in einen Automaten namens Olimpia verliebt und darüber seine Verlobte vergisst. Nachdem der Schwindel auffliegt und der Erfinder sich davongemacht hat, erwachen viele «hochzuverehrende» Herren, Damen und junge Männer wie aus einem bösen Traum: «Die Geschichte mit dem Automaten hatte tief in ihrer Seele Wurzeln gefasst, und es schlich sich in der Tat abscheuliches Misstrauen gegen menschliche Figuren ein. Um nun ganz überzeugt zu werden, dass man keine Holzpuppe liebe, wurde von mehreren Liebhabern verlangt, dass die Geliebte etwas taktlos singe und tanze [...], auch manchmal in der Art spreche, dass dies Sprechen wirklich ein Denken und Empfinden voraussetze.» Weil die Kopie die Wirklichkeit übertraf, sind die Blossgestellten verunsichert. Nathanael wird vom Wahn in den Tod getrieben. Die Gespenstergeschichte aus dem Biedermeier wirkt bis in unsere Zeit. Jacques Offenbachs phantastische Oper «Les Contes d'Hoffmann» oder das Ballett «Coppélia ou la Fille aux yeux d'émail» von Léo Délibes werden auf allen grossen Bühnen immer wieder neu inszeniert. Automaten- bauer gab es natürlich schon vor Hoffmann. In den vornehmen Salons des Rokoko begeisterten mechanische Puppen das Publikum. Schweizer Uhrmacher wie Pierre Jaquet-Droz konstruierten mechanische Objekte, die das Schreiben, Tanzen und Musizieren nachahmten. Die unzähligen Vor- und Nachfahren der leblosen Olimpia führen ein dynamisches Eigenleben. Zu ihnen gehören der Golem, Frankenstein und Roman- oder Filmfiguren wie in Alien, RoboCop, Terminator, Blade Runner und Matrix. Hoffman unterschied klar die Innen- von der Aussenwelt. Im Zwielicht von Magie und Mechanik zerstören Androiden die menschliche Ordnung. Nathanael wird verleitet, ein «sehr sauber gearbeitetes Taschenperspektiv» zu kaufen, ein dämonisches Augenpaar, eine Brille, die das ganze Psychodrama erst auslöst, weil er mit diesem toten Organersatz seine eigene körperliche Wahrnehmung verliert. Die Augenprothesen machen aus der Illusion ein Wahngebilde, ein Trugbild, dem der Überwältigte mehr vertraut als seinen Gefühlen und dem eigenen Verstand. Künstliche Nachahmungen wirken zu allen Zeiten wie eine Droge, sie machen süchtig und wecken gleichzeitig Misstrauen und Abneigung

In einem Artikel für die Zeitung «Astronauts» brachte der Luftfahrtingenieur Manfred Clynes 1960 die Neubildung «Cyborg» ins Spiel, «Cyb» für Kybernetik und «Org» für Organismus. Gemeint war die funktionale Einheit von Astronaut und Fluggerät: «self regulating man-machine systems» im Kosmos als zukünftigem Lebensraum. Ein halbes Jahrhundert später leben wir als Cyborg-Gesellschaft im Cyberland, angetrieben vom Machtdrang des Militärs und der Medizin. Wir digitalisieren das Privatleben, tragen Kleider als Wearables, vernetzen uns im Hyperraum des World Wide Web, leben als Avatare in einer virtuellen Welt, künstliche Personen in Chatrooms und Computerspielen. Zahlreiche «Schnittstellen» ersetzen das alte «Taschenperspektiv». Sie ermöglichen Dialysen, Schrittmacher und neuartige Prothesen. Die Maschine dringt ins Körperinnere. Cochlearimplantate, retinale Elektrochips und intelligente Handprothesen sind über Sensoren mit dem Nervensystem verbunden. Roboterassistierte Operationen, organische und anorganische Transplantate oder Embryonalbanken folgen einer potentiell grenzenlosen Ent- 
wicklungslogik, deren Möglichkeiten «Sciencefiction» seismographisch vorwegnehmen. Der Astrophysiker Stephen Hawking agiert als berühmtestes Sinnbild eines Cyborgs der Gegenwart. Gelähmt bis auf einen Finger der linken Hand, im hochtechnischen Rollstuhl, ausgerüstet mit Laptop und Sprachsynthesizer, erzählt er uns von schwarzen Löchern durch Raum und Zeit. Mit Witz und Selbstironie setzt er sich in Szene, lobt das vom Körper befreite Denken, seinen Fall als Schnittstelle zwischen Mensch und Maschine. Künstliche, simulierte Welten vermischen sich, für die meisten Menschen unerkennbar, mit natürlichen, aber nicht mehr selbst erfahrenen Lebensformen. Aus der gleichen Trickkiste kommen die virtuellen Experimente der Wissenschaft und die immer perfekteren Illusionen der Unterhaltungsindustrie. Wer nachdenkt, gerät ins Grübeln: War die Mondlandung real oder nur ein geschickt inszeniertes Verwirrspiel?

In den Megalopolen der Jetztzeit würde Olimpia nicht mehr auffallen, egal ob sie aus der Vergangenheit oder aus der Zukunft käme. Auch die moderne Robotik hat erkannt, dass keine Intelligenz ohne Körper möglich ist, Verkörperung oder «Embodiment» heisst die führende Erkenntnis der Forschergemeinschaft. Was für Apparate gilt, treibt auch die Menschen an. Wir waren immer schon in Versuchung, zu Maschinen zu mutieren. Hoffmann, der grosse Spezialist des Abgründigen, schreckte vor diesem Schritt zurück. Sein Nathanael endete im Wahnsinn, weil er nicht mehr unterscheiden konnte. Erst war ihm das Tote lebendig, dann das Lebendige tot. Was wird das die Nachkommen kosten, wenn sie das Echte vom Falschen nicht mehr unterscheiden können? 